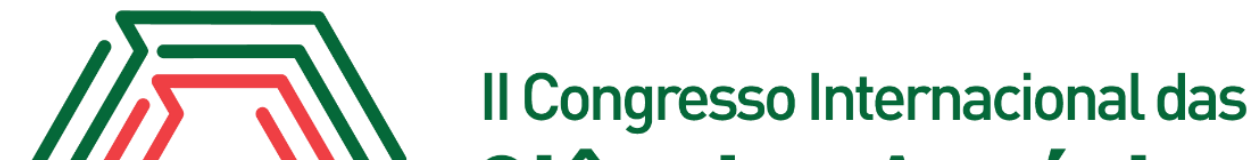 Ciências Agrárias COINTER - PDVAgro 2017
}

\section{RELATO DE EXPERIÊNCIA DA MONITORIA ACADÊMICA DE ECOLOGIA AGRÍCOLA DO CURSO DE AGRONOMIA DO IFMA-CAMPUS CODÓ}

Apresentação: Relato de Experiência

$\underline{\text { Maria Roselane Alves Oliveira }}{ }^{1}$; Carmem Valdenia da Silva Santana ${ }^{2}$; Ana Maria Silva Ferreira $^{3}$; Cristiane Nunes da Conceição ${ }^{4}$; Ayane Lima Ferreira ${ }^{5}$.

\section{Introdução}

A Monitoria, como atividade acadêmica vinculada ao desenvolvimento curricular e à formação dos alunos. Segundo Abreu et. al. (2014) auxilia no aprofundamento de conteúdos, bem como solucionar as dificuldades em relação á matéria trabalhada em aula. Desde modo, um espaço em que o acadêmico possa discutir suas dúvidas, fazer ou refazer exercícios, experimentos, desenvolvendo sua aprendizagem mediada pelo monitor. O objetivo deste trabalho foi relatar a experiência da discente no período de monitoria na disciplina de Ecologia Agrícola do curso de bacharelado em agronomia do IFMA-Campus Codó.

\section{Relato de Experiência}

A vivência na monitoria de Ecologia Agrícola se iniciou no dia 27 de abril de 2016. Durante o período da monitoria foi dada a assistência aos alunos em uma visita técnica, além de duas práticas: Compostagem e adubos verdes. Na aula prática realizou-se a limpeza da área e limitou-se o local para a preparação da leira da compostagem no local adequado.

A montagem da leira foi realizada por camadas nas seguintes sequências (uma sobre outra) na ordem: capim, esterco de caprino; restos de vegetais e frutas; palha de carnaúba; capim entre outros. Posteriormente, a preparação dos canteiros e semeio de espécies utilizadas como adubos verdes: Crotálaria; feijão guandu; feijão mungo, e milho vermelho. Os espaçamentos dos canteiros foram: $7,5 \mathrm{~m}$ x $1,10 \mathrm{~m}$, largura e comprimento.

\footnotetext{
${ }^{1}$ Agronomia, IFMA-Campus Codó, roselany.alves@hotmail.com

${ }^{2}$ Agronomia, IFMA-Campus Codó, carmem.santana@ifma.edu.br

3 Química, IFMA-Campus Codó, anna.luz@hotmail.de

4 Agronomia, IFMA-Campus Codó, cristianenunes2996@gmail.com

${ }^{5}$ Agronomia, IFMA-Campus Codó, ayaneagro14@gmail.com
} 
Quanto á monitoria, foi responsável pela elaboração do cronograma semanal da irrigação dos canteiros e o monitoramento diário da execução das atividades do cronograma pelos grupos. Ao final do período foi proposto o relatório das duas práticas como obtenção de nota parcial na disciplina mostrando os resultados possíveis do composto orgânico (Fig. 1) e adubos orgânicos. Desta maneira, foi feito aos alunos o esclarecimento de dúvidas na elaboração e como também descrever os itens essências do relatório. Por fim, o acompanhamento na visita em uma comunidade que adere o sistema PAIS (Produção Agroecológica Integrada e Sustentável) no município de Codó, metodologia de produção de hortaliças, frutíferas e criação de pequenos animais com bases agroecológicas.

Figura 1: Leira de compostagem. Fonte: Própria.

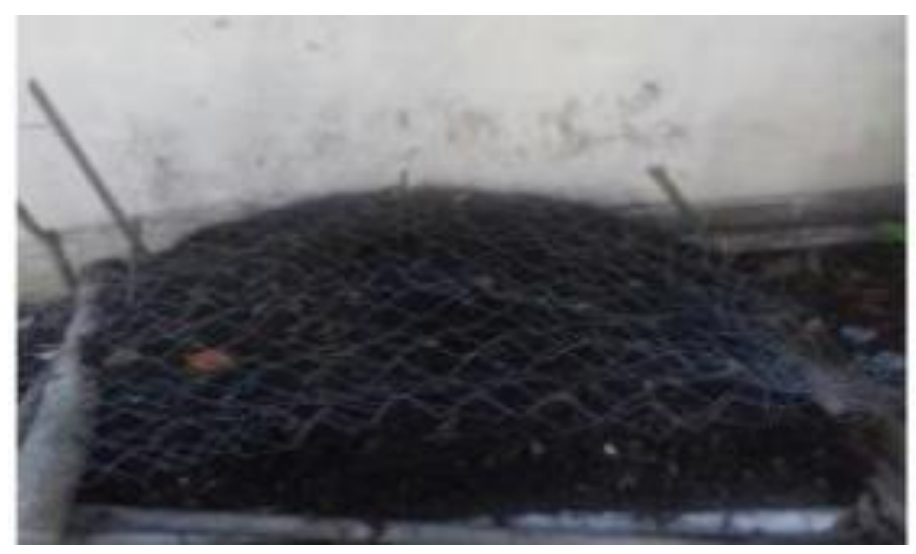

\section{Considerações}

A monitoria possibilitou trocas de experiências no convívio monitor-aluno, contribuindo para ambos no processo de ensino-aprendizagem. O professor/ orientador auxiliou no esclarecimento das dúvidas e orientações das dúvidas e orientações diante do desenvolvimento das atividades aos alunos e contribuiu também no aprofundamento do conhecimento do monitor sobre o conteúdo da disciplina.

\section{Referências}

ABREU, T. O. et al. A monitoria acadêmica na percepção dos graduandos de enfermagem. Revista de enfermagem UERJ, Rio de Janeiro, 2014 jul/ago; 22(4):507-12. p.507.

LINS, L. F. et al. A importância da monitoria na formação acadêmica do monitor. In: Jornada de Ensino, Pesquisa e Extensão da UFRPE, 9., Recife. Anais. Jepex: UFRPE, 2009. 